BMJ Open Sport \& Exercise Medicine

\section{Common health issues and advised treatments reported in an ultraendurance ocean rowing race}

To cite: Galsworthy WJH, Carr JAJ, Hearn R. Common health issues and advised treatments reported in an ultraendurance ocean rowing race. BMJ Open Sport \& Exercise Medicine 2022;8:e001120. doi:10.1136/ bmjsem-2021-001120

Accepted 9 November 2021
Check for updates

(c) Author(s) (or their employer(s)) 2022. Re-use permitted under CC BY-NC. No commercial re-use. See rights and permissions. Published by BMJ.

${ }^{1}$ GKT School of Medical Education, King's College London, London, UK

${ }^{2} S$ chool of Life Course and Population Science, King's College London, London, UK

Correspondence to Dr Russell Hearn; russell.hearn@kcl.ac.uk

\begin{abstract}
Objectives 0cean rowing is an extreme ultraendurance sport where individuals row unsupported across an ocean. This can mean months at sea in unpredictable and inhospitable conditions. The extreme physical and mental demands associated mean medical issues are common yet under researched, impacting the medical assistance provided.
\end{abstract}

Methods The Talisker Whisky Atlantic Challenge provides a framework with safety protocols to create safer environments for athletes to attempt transatlantic crossings. Race logs, which record communication between rowers and safety teams, were anonymised and examined to create cumulative totals of medical issues requiring help and an incident timeline.

Results Duty officers were notified of 65 medical complaints, $32 \%(n=21)$ requiring race doctors. Dermatological conditions were most common, accounting for $32 \%$ of complaints $(n=21)$ and affecting $24 \%$ of rowers. Pressure sores and infections represented $43 \%$ and $38 \%$ of dermatological complaints respectively. Musculoskeletal injuries equalled $18 \%(n=12)$ of complaints, affecting $20 \%$ of rowers. Most cases were reported in weeks one and three, with $37 \%(n=24)$ of issues and $90 \%(n=10)$ of seasickness cases in week one. Hygiene and antibiotics were frequently advised management options.

Conclusion Conditions requiring race doctor input represent the most severe cases with the potential to deteriorate. Managing dermatological and musculoskeletal issues is vital throughout the race, while seasickness prophylaxis and education is essential in initial race stages. Infections are cause for concern, with gluteal pressure sores a potential route for secondary infections. Further research is required before evidence-based guidelines for management of health issues in ocean rowers can be introduced.

\section{INTRODUCTION}

The Indian, Pacific and Atlantic Oceans have drawn athletes from around the world since Frank Samuelsen and George Harbo completed the first ocean row in 1869 . Combining extreme ultraendurance with some of the world's harshest and unpredictable environments, ocean rowers are isolated at sea for months, facing intense mental and physical challenges. The founding of various

\section{Key messages}

What is already known

- Very little is currently known about the common health issues facing this population of ultra-athletes.

- Only one paper with limited participant numbers has sought to examine these common medical complaints using self-reported means.

What are the new findings

- Dermatological and musculoskeletal conditions appear to acutely affect rowers prompting them to seek help.

- Infections present a valid cause for concern and race doctors should review both antibiotic choices at sea and effective analgesia for athletes. A full medication review is encouraged.

- Rower education may help prevent musculoskeletal injury and illness as well as aid self-management when at sea.

transoceanic races has increased accessibility to this emerging sport by providing frameworks and safety measures for adventurers planning their expeditions. However, despite this expanding popularity, shared knowledge of the physiological and medical challenges faced is limited, with a lack of agreed evidencebased advice and guidance.

The Talisker Whisky Atlantic Challenge (TWAC) is an annual transatlantic rowing race held each December. Rowers leave the Canary Islands to row 3000 nautical miles to Antigua. ${ }^{1}$ They spend months at sea in specially designed boats, rowing shift patterns such as 2 hours on 2 hours off, day and night. ${ }^{2}$ Rowers must be deemed medically fit by their own general practitioners before departure and TWAC mandates that all boats must carry a full race specified medical kit, plus satellite phones and tracking beacons. Medical kits are extensive and include analgesic drugs of various strengths, antibiotics, wound dressings, eye, gastrointestinal and allergy medications, skin topicals, and basic dental kits. 
TWAC duty officers are responsible for monitoring rower health and safety at sea, acting as a link between crews and race officials. They also serve as a primary method of contacting medical support during the race, with all rower conversations recorded in race logs. Duty officers and the race doctor are available at all hours via satellite phone and can divert race safety yachts to aid a stricken team or ill participant when necessary. The TWAC race doctor is an orthopaedic trauma surgeon with extensive knowledge in both extreme physiology and austere medicine.

Limited research has been carried out regarding the medical issues facing ocean rowers and has often focused on small sample sizes, ${ }^{2-4}$ or individual case studies. ${ }^{5}$ Studies have also typically examined specific issues or narrow subpopulations within the sport. For instance, one study examined the incidences of nonfreezing cold injuries in long-distance polar rowers, noting that the feet are most commonly affected. ${ }^{4} \mathrm{~A}$ further case study described the physical and psychological experiences of a solo rower. Positive correlations between perceived exertion and pain were noted, along with various coping strategies that aided pain management. ${ }^{5}$ Another case study outlined a meal planning model that was successfully implemented into an ocean rowing team participating in a transoceanic race. ${ }^{6}$ Finally, research into the physiological changes associated with the sport in four athletes noted raised levels of proinflammatory and decreased anti-inflammatory markers. ${ }^{2}$ Only one study has explored the full spectrum of medical issues encountered during a transatlantic race by recording the experiences of 23 individual competitors. ${ }^{3}$ This research found that dermatological problems affected the majority of rowers, while tendonitis and mental health symptoms, including hallucinations and panic attacks, were also common. ${ }^{3}$ As a result of limited research exploring common conditions, there is a lack of codified medical guidance for race doctors and remote management protocols for these ultra-athletes at sea.

This study aims to provide a comprehensive report of the medical complaints requiring assistance encountered in the 2018 TWAC race. Developing our understanding of these problems and predicting where in the race they could occur, is vital to keeping these ultra-athletes safe through physical preparation, medical advice and training.

\section{METHODS}

\section{Data collection}

Ocean rowing and race demographics were obtained from the TWAC race website. ${ }^{7}$ Information relating to rowers' health, with any treatments advised, was gathered from the 2018 TWAC race logs collected by the race organisers, Atlantic Campaigns. These logs consisted of data entries into a Microsoft Word table specific to each satellite phone call received regardless of whether the participant, or team, required rescue or were able to continue with the race. Entries state a conversation's
Table 1 Participant and ocean rowing demographics from self-reported data

\begin{tabular}{|c|c|}
\hline Participants (n) & 88 \\
\hline \multicolumn{2}{|l|}{$\operatorname{Sex}(n)$} \\
\hline Male & 66 \\
\hline Female & 22 \\
\hline No. of teams participating (n) & 28 \\
\hline Successful (n) & 86 (27 teams) \\
\hline Rescued (n) & 2 (1 team) \\
\hline \multicolumn{2}{|l|}{ Teams (n) } \\
\hline Solo rowers & 5 \\
\hline Pairs & 5 \\
\hline Trios & 2 \\
\hline Fours & 13 \\
\hline Fives & 3 \\
\hline Time at sea, mean (SD) (days) & $48(14)$ \\
\hline
\end{tabular}

date and time, name of the duty officer receiving the call, team or rower name, information on the issue raised and comments made by the duty officers. Atlantic Campaigns agreed to share their anonymised 2018 race log for the purposes of advancing research in this field. The data was anonymised by Atlantic Campaigns prior to analysis by removing both rower and team names and any remaining identifiable information.

\section{Analysis}

Health issues were categorised by medical system and cumulative totals produced alongside the frequencies of each complaint with respect to rower time at sea. Management options recommended by either the duty officers or race doctors were also noted and totalled. Data are presented graphically with complaint incidence in relation to participant time at sea. Where $n>10$, the total number of complaints or intracategory frequency was included alongside the complaint percentage. Where averages were determined, results are noted as mean \pm SD.

\section{Patient and public involvement}

Patients and/or the public were not involved in the design, or conduct, or reporting, or dissemination plans of this research.

\section{RESULTS}

Participant and ocean rowing demographics relating to the 2018 TWAC race are presented in table 1 . The average time at sea was $48 \pm 14$ days and ranged from six to 76 days. Twenty-eight teams took part in the race made up of a total of 88 rowers, the majority of whom were male. $(75 \% ; n=66)$ Teams of four were the most common $(59 \%$ of rowers; $n=13$ ), $17 \%$ were teams of five, $11 \%$ pairs, $7 \%$ trios and $6 \%$ were solo rowers. Ninety-six percent of teams were successful in completing their row with only one team (two rowers) requiring rescue after six days at 
Table 2 Health issues reported to the duty officers during the 2018 TWAC

\begin{tabular}{ll}
\hline Complaint & $\begin{array}{l}\text { Incidence } \\
\text { (n) }\end{array}$ \\
\hline Dermatological & 21 \\
Musculoskeletal & 12 \\
Seasickness & 11 \\
\hline Gastrointestinal & 6 \\
\hline Loss of appetite & 5 \\
\hline Fever/temperature & 2 \\
\hline Dental & 2 \\
\hline Mental Health & 1 \\
\hline Urological & 1 \\
\hline Upper respiratory tract infection & 1 \\
\hline Nose bleeds & 1 \\
\hline Haemorrhoids & 1 \\
\hline Dehydration & 1 \\
\hline
\end{tabular}

TWAC, Talisker Whisky Atlantic Challenge.

sea. Information relating to the reason for rescue was not found in the race logs or was unable to be determined due to anonymisation.

The 2018 TWAC medical race log is outlined in table 2 . Race duty officers were notified of 65 medical complaints, with race doctors consulting on $32 \%$ of cases $(n=21)$. Dermatological complaints were the most common, accounting for $32 \%$ of cases $(n=21)$ and affecting $24 \%$ of rowers. This was followed by musculoskeletal injuries representing $18 \%(n=12)$ of issues and reported by $20 \%$ of participants. Severe seasickness affected $13 \%$ of rowers ( $17 \%$ of total complaints reported; $n=11$ ), gastrointestinal illness $(9 \%)$ and loss of appetite $(8 \%)$. A comprehensive breakdown of these health issues is presented in figure 1 . Most dermatological cases were related to pressure sores

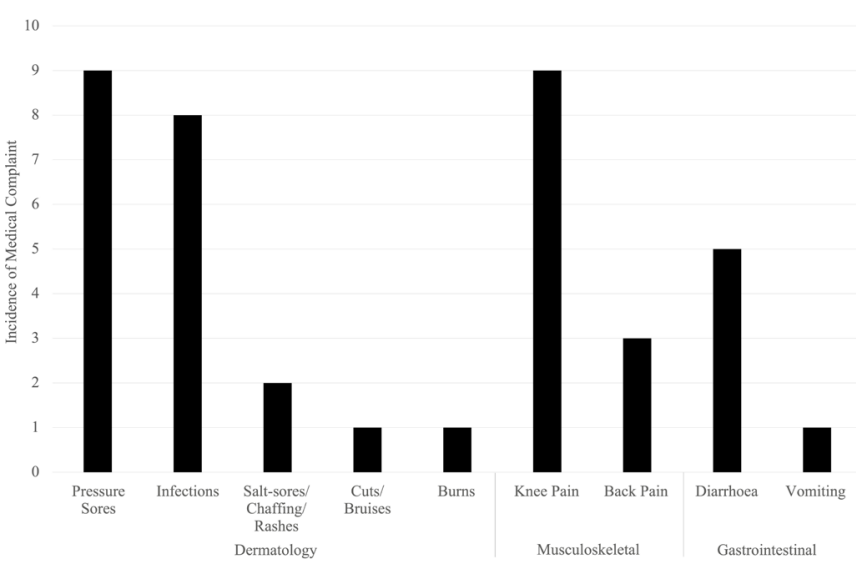

Figure 1 Race log reported incidences of dermatological, musculoskeletal and gastrointestinal complaints were further broken down into specific problems. Pressure sores and infections were the most common dermatological problems while knee pain and diarrhoea were the most common musculoskeletal and gastrointestinal problems, respectively.
$(43 \%)$, which were found in $10 \%$ of rowers, or infections (38\%). Musculoskeletal complaints consisted of knee and back pain ( $75 \%$ and $25 \%$, respectively), with knee pain reported in $10 \%$ of the total fleet. Diarrhoea was the main gastrointestinal problem, accounting for $83 \%$ of gastrointestinal complaints and reported by $6 \%$ of competitors.

In relation to length of time at sea, figure 2 , the first week reported the greatest number of medical complaints, equating to $37 \%$ of all reported problems $(n=24)$ with the race doctor consulting on $33 \%$ of these. Seasickness was the most prevalent condition facing rowers within the first week, with $11 \%$ of participants affected $(n=10 ; 90 \%$ of all seasickness cases). Fifty percent of reported musculoskeletal complaints and $44 \%$ of the total reported knee pain occurred in this first week. Gastrointestinal and dermatological problems were also noted but to a lesser degree.

Week three had the second highest frequency of medical complaints $(20 \% ; \mathrm{n}=12)$ and the highest incidence of dermatological problems (38\% of dermatological issues), affecting 9\% of competitors. Pressure sores accounted for $50 \%$ of dermatological cases reported during this week. Dermatological issues were also the most common complaint on a weekly basis, reported in seven of the total 11 weeks.

From week four onwards the frequency of medical issues reported to race staff reduced, with an average of approximately three conditions reported weekly. The first successful team completed their row after 34 days at sea (week six) with most competitors finishing between weeks six and nine. The remaining two competitors completed the race in week 11 with the last boat finishing after 76 days at sea.

The various medications and management options advised by either race duty officers or doctors are shown in figure 3. In all, 18 incidences of medication advice and nine cases of hygiene measures were noted. Antibiotics were the most common medications advised while analgesia and the management of gastrointestinal issues formed the bulk of the other advised treatments.

\section{DISCUSSION}

This report details the medical issues faced by transatlantic rowers requiring remote management by race doctors and support staff. Conditions serious enough to require external advice represent the most problematic issues facing ocean rowers, however these reflect only a small fraction of the total issues encountered by rowers at sea. Understanding the frequency, severity and optimal management of these medical problems can aid risk mitigation, selection of onboard medication and the education of future rowers.

The high incidence of dermatological issues reported weekly reflect the detrimental impact these problems have on a rowers' functioning at sea. A wet, salty and high stress environment can facilitate skin breakdown, especially in already damaged areas of skin. ${ }^{8}$ Gluteal pressure 


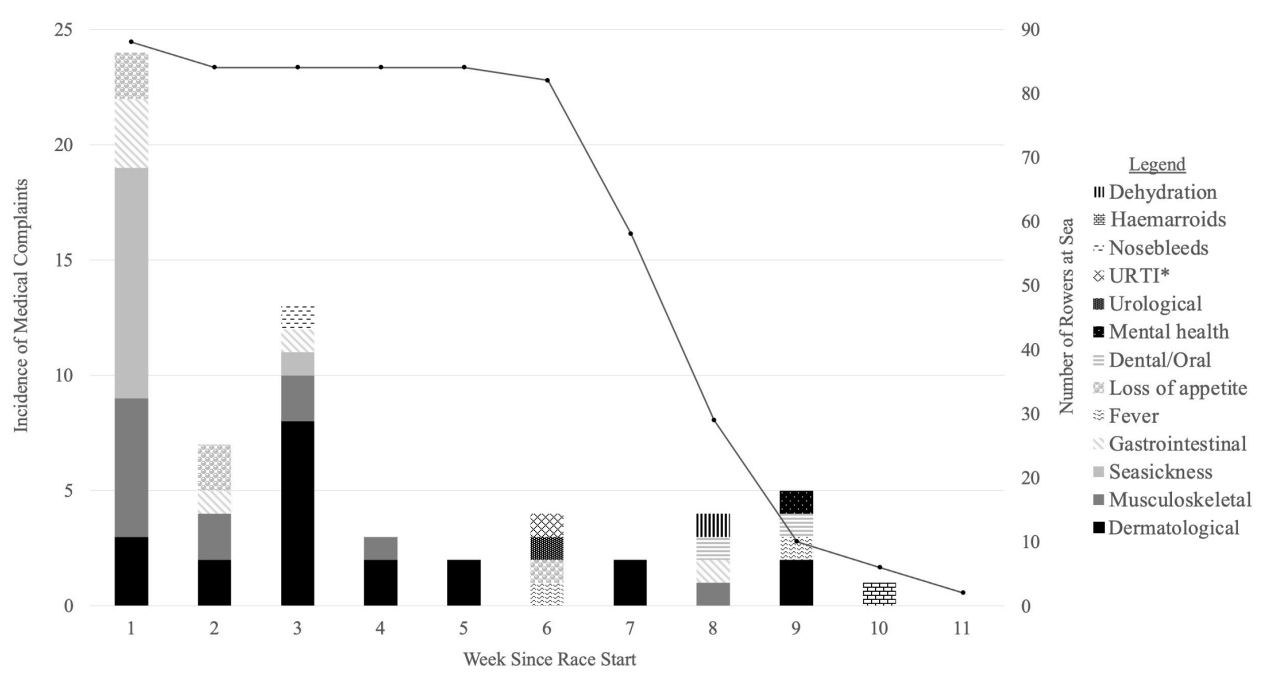

Figure 2 Cumulative totals of injuries and illnesses are shown alongside the number of rowers at sea and the week since race start. Most incidents occurred within the first three weeks of the race with dermatological and musculoskeletal complaints alongside seasickness all prevalent. Most rowers finished the race within weeks six to nine with the last two rowers arriving in week 11. *URTI, upper respiratory tract infection.

sores were the most common complaints and are potentially some of the most problematic wounds considering their anatomical location. This may explain the high concurrent infection and pressure sore rates seen in the 2018 TWAC race logs.

Techniques employed by disabled athletes may aid ocean rowers by encouraging regular weight distribution changes, padding and use of bio-occlusive dressings. ${ }^{9}$ Barrier creams and skin protection are also key for preventing skin or wound deterioration at sea and rowers should be advised about these measures prior to departure. ${ }^{8}$ The hygiene and antiseptic measures recommended are among the most important interventions. Septic wounds caused by a progressive infection can have serious consequences where medical intervention is limited. Hygiene and antiseptic measures should therefore be included in rower education as preventative practice.

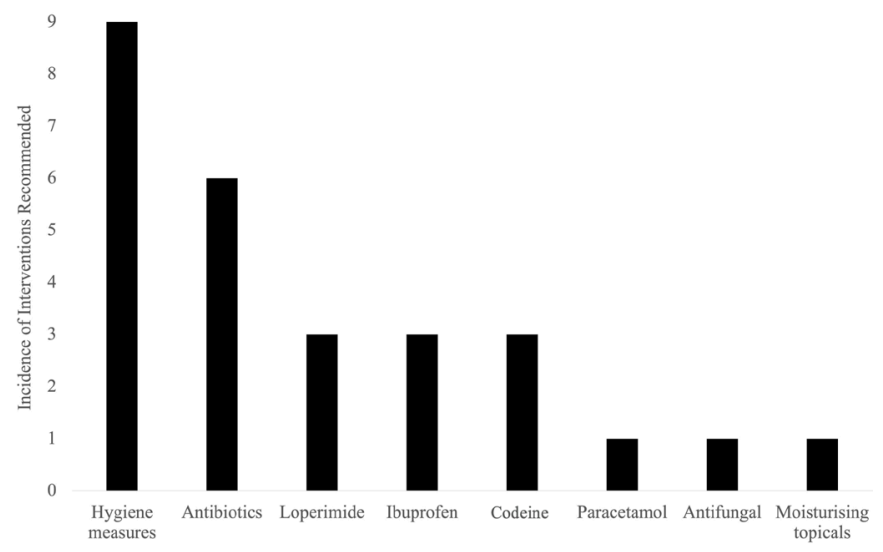

Figure 3 The incidence of various medications that were advised by the duty officers or race doctors during the 2018 TWAC race. Hygiene, antibiotics and analgesia formed the bulk of reported advice provided. TWAC, Talisker Whisky Atlantic Challenge.
Antibiotic choices at sea are presumptive and clinical decisions made without confirmation by culture. Where rowers do not have the ability to send wound photographs, decisions are made by the race safety team without clear confirmation of concern. Knowledge of common maritime pathogens, such as community- associated methicillin-resistant Staphylococcus aureus (ca-MRSA), ${ }^{10}$ is needed and should be planned for in advance, with antibiotic stewardship respected and rower education a priority.

Inshore rowers commonly report musculoskeletal injury to the lower back, and occasionally knee pain, often caused by excessive loading. ${ }^{11-14}$ Risk factors for lower back pain in these rowers include: rowing for more than 30 minutes; rapid increases in training, competition loads and intensities; previous lower back problems; rough water; fatigue or poor technique. ${ }^{15}$ Ocean rowers can row between 10 and 16 hours a day for months at a time. ${ }^{236}$ This constant motion can overload lower lumbar regions and knee joints causing pain similar to inshore rowers (figure 1). Incidences of severe knee pain could also be caused by foot steering systems. This twisting motion, together with rough sea-states, throws rowers off balance mid-stroke, causing awkward loading of the knee joints. Educating rowers in effective pain management progression and the biomechanics of their injuries may help them effectively manage pain and limit joint strain.

Musculoskeletal complaints were common throughout the race, especially in the first four weeks. Ocean rowing is an amateur sport, with limited professional guidance in rower preparation and training. This may leave athletes inadequately prepared for the physical challenges involved and explain the high volume of musculoskeletal injuries seen early in the race. Further research into appropriate pre-race strength training programmes, with exercise regimes adapted to the individual, may aid rower preparation and reduce injury frequencies. 
Regular monitoring of a rower's pain levels using standardised rating scales will help determine severity, and when longer lasting injuries might benefit from a multidisciplinary approach. ${ }^{16}{ }^{17}$ Screening for previous lower back pain may help susceptible rowers better prepare and manage any symptoms experienced at sea. Performing different exercises while at sea may be difficult, but modifications to a rower's shift pattern may help provide time for recovery management. Awareness of associated neurological symptoms or decline in mental health is essential to ensure rower safety at sea and directing further investigations and management. ${ }^{15}$

Use of paracetamol, ibuprofen and codeine were all reported in race logs, however, various physical and psychological coping strategies can also be employed to manage an ocean rower's low-level background pain. ${ }^{5}$ Simultaneous practice of psychological coping strategies with the proper use of an effective analgesic ladder could be crucial in providing holistic care and determining expedition success, provided athletes are properly educated in their uses. ${ }^{5} 1819$ While guidelines for the management of musculoskeletal pain exist for river rowers, ${ }^{15}{ }^{17}$ further research is required before a consensus can be reached on practice guidelines for ocean rowers where limited resources are available.

Diarrhoea was the most common gastrointestinal complaint among the 2018 TWAC fleet. Possible causes include high levels of stress or a sudden change in diet, with rowers living off freeze-dried foods and consuming up to $33.5 \mathrm{MJ}(8000 \mathrm{kcal})$ a day. ${ }^{6}$ These factors may also explain the high concurrent prevalence of loss of appetite in the first threeweeks of the race. Exposure to this diet pre-departure may help athletes adjust to these changes earlier. Extreme exercise and a hot climate, together with vomiting and diarrhoea, could well lead to dehydration and exhaustion. Symptom monitoring and promoting steady hydration are key to prevent further deterioration. Avoiding the contamination of the living environment and the illnesses associated with poor hygiene is also crucial. Without definitive testing it is hard to elicit the cause of gastrointestinal issues, especially where a high prevalence of other infections is noted. Therefore, infective causes such as gastroenteritis cannot be ruled out. Gastrointestinal infections could occur at any stage during the race and may explain any reported incidences in latter stages (week eight). Effective antibiotic choices should therefore be available for use at sea at the race doctor's discretion.

High levels of severe seasickness were seen during the first week of the race and may associate with reports of a loss of appetite. Smaller vessels such as ocean rowing boats will pitch and roll more than larger boats and it is not surprising that high incidences of motion sickness were reported. Severe seasickness is debilitating, emphasising the importance of preventative measures to reduce impact. Interestingly, no recommendations to start antimotion sickness medications were reported in the race logs and might mean rowers were already self-medicating. However, educating rowers to prevent and manage symptoms through a combination of behavioural measures, adaptation and drug therapies may help reduce incidences and severity. ${ }^{20}$ Examples of behavioural changes include fixing visual gaze on the horizon, sleep and controlled breathing, while adaptation to the sea's motion can take a few days. ${ }^{2021}$ Medications such as scopolamine are effective pharmacological agents with both rapid and longer acting prophylactic forms..$^{20}$ Rowers should be educated on how to appropriately apply patches or administer these medications effectively.

The latter stages of the race (week six onwards) highlighted other concerns from dental issues to haemorrhoids, severe enough to seek assistance. Factors such as length of time at sea, weather and competitor abilities may all contribute to these varied medical conditions. Race medics and safety teams should therefore plan for many different health issues and be prepared to manage potentially large numbers of athletes isolated at sea over long periods of time.

\section{Limitations}

This study examines only the 2018 TWAC logs and so draws from a limited population when discussing conclusions and recommendations. Fluctuations year to year in weather, crew age and health, as well as changes in medical kit would all likely combine to produce variation in the frequency of illness and musculoskeletal injury seen in the racing population. Additionally, race logs record only the injuries that were reported to safety crews, and it is reasonable to assume that further minor conditions went unreported. This study sought to examine the health issues severe enough to require help and guidance, yet with a lack of a severity rating system, limited conclusions can be drawn. Furthermore, issues may have appeared weeks earlier than they were reported to duty officers, creating a disparity between actual and reported onset. Due to anonymisation and only having access granted to the race logs, other relevant information is missing such as rower age, and prior medical records, making it difficult to infer more in-depth conclusions from the data. Lacking knowledge of past medical problems means it is unclear whether some of the issues reported represent a new condition or the reoccurrence or worsening of preexisting problems. Future analysis in this field may seek to address many of these limitations and further expand on the findings presented here.

\section{CONCLUSIONS}

Rowing the Atlantic is an arduous and gruelling task pitting athletes against extreme conditions, social isolation and physical exhaustion. The TWAC race provides a means for ocean rowers to undertake this challenge with safety teams monitoring their health and well-being. As popularity for this sport continues to grow it becomes increasingly important to understand the common medical problems athletes are at risk of and to develop best practices to guide self-management remotely. This retrospective examination of the TWAC 2018 race logs demonstrated that dermatological and musculoskeletal conditions are frequently experienced at sea and present 
a continuous challenge to rowers throughout the duration of a transoceanic race. Seasickness is also frequently experienced by athletes although largely occurs in the first week at sea. Infection is a persistent concern with hygiene and antiseptic measures, followed by antibiotic recommendations, the most frequently advised managements. Most conditions were reported within the first three weeks of the race. Recommendations to educate rowers on pain management, preventative measures and use of topical barrier creams may improve crew well-being and care. Further research is needed before evidence based medical guidance can be produced to serve this challenging and unique patient population.

\section{Twitter Russell Hearn @rustlehearn}

Acknowledgements The authors would like to thank Atlantic Campaigns for their support in aiding this research and Dr Marian Huett for her advice.

Contributors Study concept and design (WJHG, JAJC and RH); data acquisition (WJHG and JAJC); data analysis (WJHG and JAJC); drafting of manuscript (WJHG and JAJC); critical revision of manuscript (WJHG, JAJC and RH); approval of final manuscript (WJHG, JAJC and RH); guarantor (RH).

Funding The authors have not declared a specific grant for this research from any funding agency in the public, commercial or not-for-profit sectors.

Competing interests None declared.

Patient consent for publication Not applicable.

Ethics approval Approval was gained from the King's College London's Research and Ethics Committee-reference LRU-19/20-14601.

Provenance and peer review Not commissioned; externally peer reviewed.

Data availability statement Data are available on reasonable request.

Open access This is an open access article distributed in accordance with the Creative Commons Attribution Non Commercial (CC BY-NC 4.0) license, which permits others to distribute, remix, adapt, build upon this work non-commercially, and license their derivative works on different terms, provided the original work is properly cited, appropriate credit is given, any changes made indicated, and the use is non-commercial. See: http://creativecommons.org/licenses/by-nc/4.0/.

\section{ORCID iD}

Russell Hearn http://orcid.org/0000-0002-6909-7395

\section{REFERENCES}

1 Atlantic Campaigns. The challenge: Talisker Whisky Atlantic challenge. Available: https://www.taliskerwhiskyatlanticchallenge. com/the-challenge/ [Accessed 30 Mar 2021].
2 Keohane DM, Woods T, McCarthy Y, et al. A repeated-measures case series of physiological responses to a transoceanic rowing race. Int J Sports Med 2019;40:152-7.

3 Carron M, Coulange M, Dupuy C, et al. Preparation and medical follow-up for a single-handed transatlantic rowing race. Int Marit Health 2017;68:7-11.

4 Longman DP, Brown EL, Imray CHE. Nonfreezing cold injuries among long-distance polar rowers. Wilderness Environ Med 2020;31:209-14.

5 Alschuler KN, Whibley D, Alberts NM, et al. The physical and psychological experience of rowing the North Atlantic solo and unassisted. Wilderness Environ Med 2020;31:144-50.

6 Clark N, Coleman C, Figure K, et al. Food for trans-atlantic rowers: a menu planning model and case study. Int J Sport Nutr Exerc Metab 2003;13:227-42.

7 Atlantic Campaigns. 2018 race entrants: Talisker Whisky Atlantic challenge. Available: https://www.taliskerwhiskyatlanticchallenge. com/2018-race-entrants/ [Accessed 30 Mar 2021].

8 Loddé B, Mahé C, Jacolot L, et al. Skin diseases affecting highlevel competition sailors: descriptive study carried out during the 2012 AG2R transatlantic boat race. Wilderness Environ Med 2016;27:39-45.

9 Klenck C, Gebke K. Practical management: common medical problems in disabled athletes. Clin J Sport Med 2007;17:55-60.

10 Lucas R, Boniface K, Roberts K, et al. Suspected methicillinresistant Staphylococcus aureus infections at sea. Int Marit Health 2007;58:93-102.

11 Thornton JS, Vinther A, Wilson F, et al. Rowing injuries: an updated review. Sports Med 2017;47:641-61.

12 Smoljanovic T, Bojanic I, Hannafin JA, et al. Traumatic and overuse injuries among international elite junior rowers. Am J Sports Med 2009;37:1193-9.

13 Smoljanović T, Bohaček I, Hannafin J, et al. Sport injuries in international masters rowers: a cross-sectional study. Croat Med $J$ 2018;59:258-66.

14 Trease L, Wilkie K, Lovell G, et al. Epidemiology of injury and illness in 153 Australian international-level rowers over eight international seasons. Br J Sports Med 2020;54:1288-93.

15 Wilson F, Thornton JS, Wilkie K, et al. 2021 consensus statement for preventing and managing low back pain in elite and subelite adult rowers. Br J Sports Med 2021;55:893-9.

16 Evans G, Redgrave A. Great Britain rowing team guideline for diagnosis and management of rib stress injury: Part 1. Br J Sports Med 2016;50:266-9.

17 Hainline B, Turner JA, Caneiro JP, et al. Pain in elite athletesneurophysiological, biomechanical and psychosocial considerations: a narrative review. Br J Sports Med 2017;51:1259-64.

18 Anekar AA, Cascella M. WHO Analgesic Ladder. [Updated 2021 May 18]. StatPearls.

19 Alschuler KN, Kratz AL, Lipman GS, et al. How variability in pain and pain coping relate to pain interference during multistage ultramarathons. Pain $2019 ; ; 160: 257-62.1$.

20 Schmäl F. Neuronal mechanisms and the treatment of motion sickness. Pharmacology 2013;91:229-41.

21 Shupak A, Gordon CR. Motion sickness: advances in pathogenesis, prediction, prevention, and treatment. Aviat Space Environ Med 2006;77:1213-23. 